\title{
PREMATURE EPIPHYSIAL FUSION AT THE KNEE JOINT IN TUBERGULOUS DISEASE OF THE HIP
}

\author{
W. Parke, G. S. Colvin, and A. H. G. Almond, Liverpool, England
}

The treatment of tuberculous disease of the hip in children has not yet reached the stage when useful recovery of joint function is a frequent end-result. Brackett (1924) urged that the first objective should be the provision of a permanently safe and useful limb; and in girls, we would add, a graceful one. These standards are not achieved, even with quiescent disease and a soundly ankylosed joint, if there has been arrest of limb growth at an early age. As long ago as 1899 Sir Robert Jones estimated the frequency of this complication to be in the region of 15 per cent.; but it was not until 1944 that Gill showed that it was caused by premature epiphysial fusion at the knee joint and drew further attention to the severity of the disability.

This review was undertaken to determine the present incidence of premature epiphysial fusion in children who had been treated for tuberculous disease of the hip by prolonged conservative measures; and to study the relationship of this complication to the disease, the changes which precede and accompany premature fusion, and the possibilities of earlier recognition and prevention.

The patients were treated at four hospitals in the Liverpool area: Alder Hey Children's Hospital; Liverpool Open-Air Hospital; Royal Liverpool Children's Hospital; and Wrightington Hospital. The study included all patients with tuberculous disease of the hip joint who were in-patients of these hospitals during 1947, except those in whom the disease first began after the age of fifteen years. There were ninety-one diseased hips in ninety patients-forty-two right, forty-nine left; forty-seven male, forty-four female; with a duration of disease varying from four months to twenty-two years. In addition to general study of the clinical and radiographic findings the examination included individual mensuration of the long bones, and X-ray films of both hips, both knees, and both ankles.

\section{CLINICAL EVIDENCE OF PREMATURE FUSION}

The later stages of premature epiphysial fusion, so well described by Gill (1944), Kestler (1947), and Ross (1948), are recognised easily by deformity at the knee and measurable shortening. We were unable to discover any reliable clinical sign of early fusion in limbs with equal bone length and without deformity. There were, however, definite clinical signs of osteoporosis which, as will be seen later, is considered to be a necessary forerunner of premature fusion. Knees which have been immobilised for one year or more show wellmarked tenderness of the bones to pressure-tenderness which bears a direct relationship to the degree of osteoporosis. In one case, with moderate pressure, it was possible to indent the cortical bone over the lateral condyle of the femur; release of pressure resulted in recoil as would an old ping-pong ball. These signs are evidence of no more than osteoporosis which may not yet be associated with premature fusion. Conversely, bones which show indisputable evidence of premature fusion are not always tender; in such cases radiographic examination shows that reformation of bone has occurred with dense and irregular trabeculation. Circumferential limb measurements were found to be of no diagnostic value.

\section{RADIOGRAPHIC EVIDENCE OF EARLY PREMATURE FUSION}

The complication is always preceded by intense porosis of the bones at the knee. The earliest stage is shown by flame-shaped areas of increased translucency in the diaphyses and epiphyses, with their apices at the points of entry of the nutrient arteries and their bases on the articular cartilage (Fig. 1). With further resorption of bone there is marked loss of 


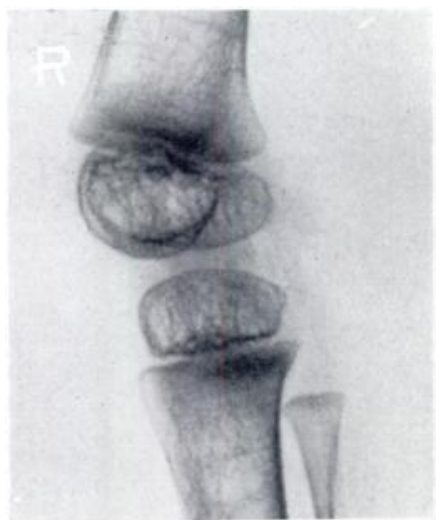

Fig. IA

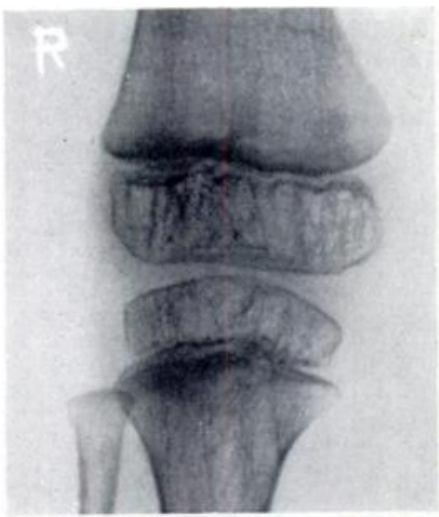

FIG. $1 \mathrm{C}$

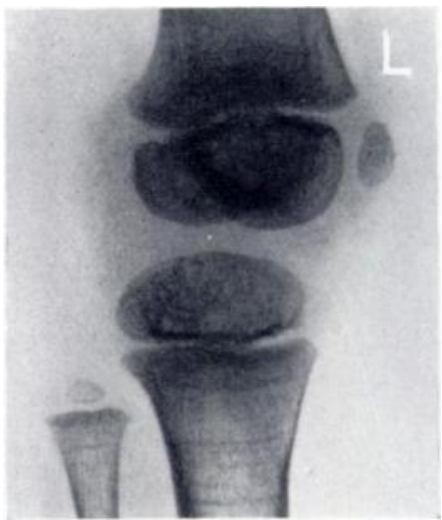

IIG. 1 B

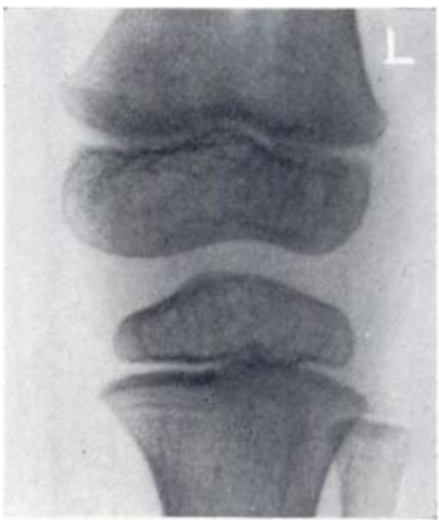

FIG. $1 \mathrm{D}$

Case 8() . 1)isease of the right hip joint, showing osteoporotic and toxaemic changes in the region of the right knee.

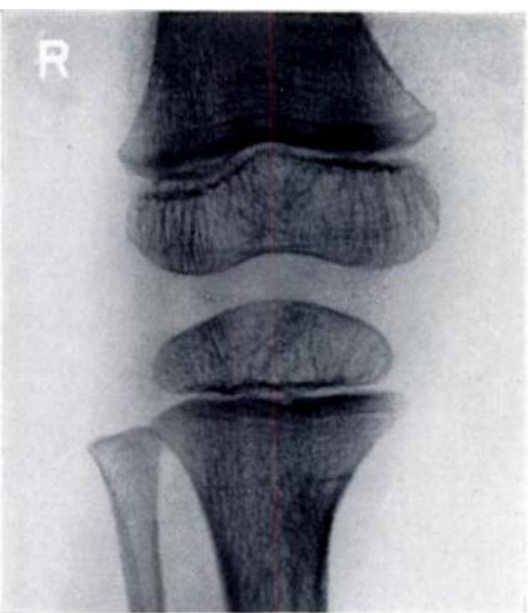

FIG. 2A

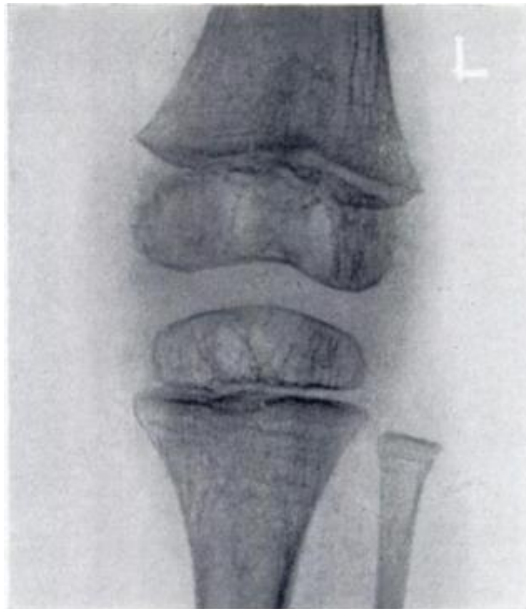

FIG. 2B

(ase 43. Disease of the left hip joint, showing central areas of resorption in the lower femoral and upper tibial epiphyses of the left knee. 
transverse trabeculation. This is more evident in the diaphyses some distance from the epiphysial lines where the medullary bone takes on a frosted glass or irregular honeycomb appearance. There is also thinning of the cortical bone. At this stage it is often found that the circumferential size of the bones on the affected side is smaller, and the vertical depth of the epiphysial plates reduced. On the normal side the bones show less marked porosis, and their size and the depth of the epiphysial plates remain unchanged (Fig. 1).

The apparent solution of transverse trabeculation brings into focus the finer points of the longitudinal trabecular architecture of the epiphyses. In the tibial epiphysis this consists of oblique cancellous struts which pass from the near-central area of the terminal bone plate to the articular cartilage of the opposite condyle, with an infero-medial decussation. Laterally they are less oblique, do not cross, and pass almost vertically to the condyle of the same side. In the lateral view the struts are situated behind the centre; they pass upwards and forwards

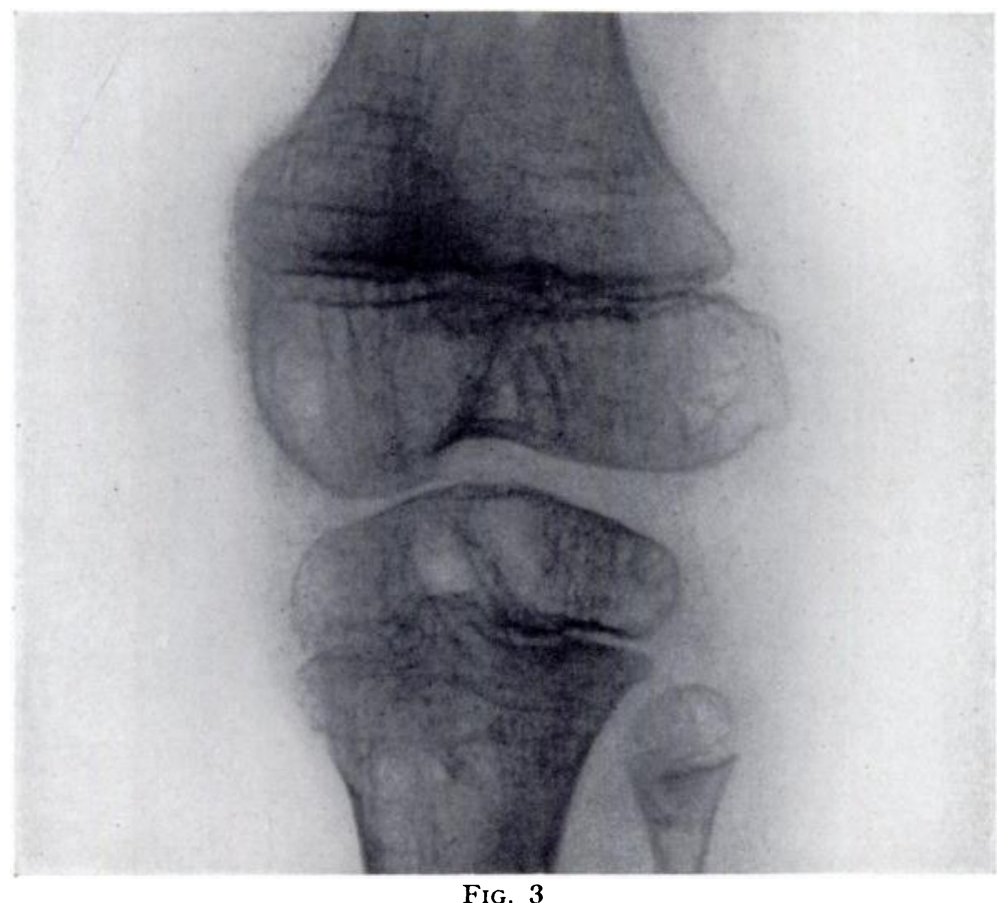

Case 25. Disease of the hip joint, showing the first stages of a bulge into the area of resorption in the tibial epiphysis.

to the articular cartilage and are continuous with similarly arranged struts in the diaphysis. The femoral epiphysis is strengthened by two bars which pass vertically downwards from the terminal bone plate to the articular cartilage of each condyle, which likewise are stronger posteriorly and continuous with similarly arranged struts in the diaphyses (Fig. 4). Increasing osteoporosis gives rise to resorption of the longitudinal trabeculation in the weakest places, with the formation of completely translucent areas in the epiphyses and occasionally in the diaphyses (Fig. 2). Their appearance heralds the approach of premature fusion. Subsequent changes at the femoral and tibial epiphysial lines are not identical and will be described separately.

"Bulge type" of fusion-In the tibial epiphysis, a central translucent area appears to the inner side of the mid-line above the point of strut decussation, and enlarges upwards towards the articular cartilage and downwards towards the terminal bone plate (Fig. 3). The terminal bone plate, the thinned cartilaginous plate, and the growth retardation line, together with

VOL. $31 \mathrm{~B}$, No. 1 , FEBRUARY 1949 


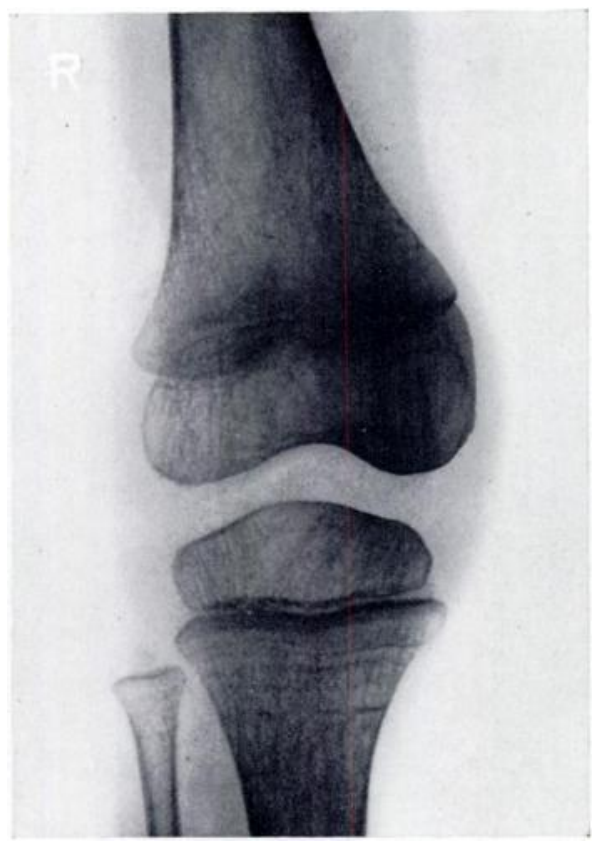

FIg. 4A

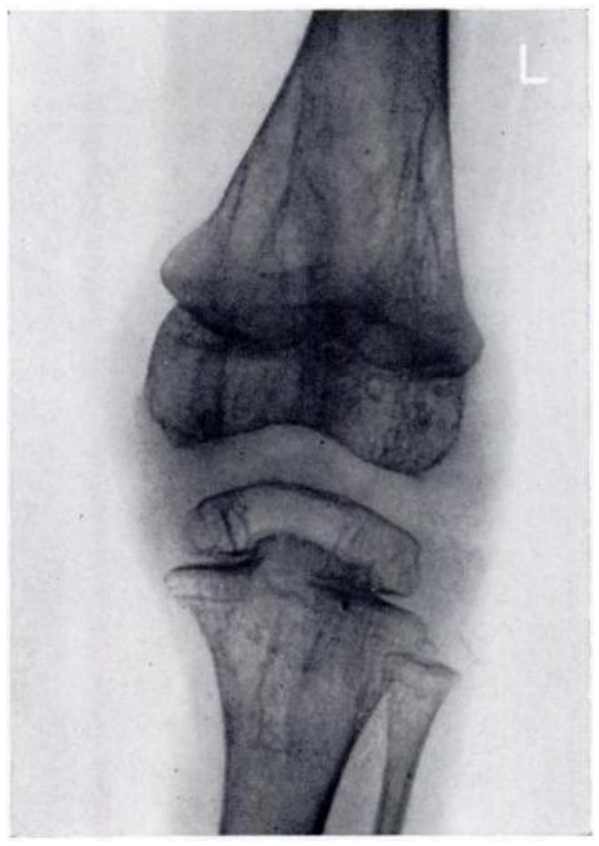

FIG. 4B

Case 77. Disease of the left hip joint with an unruptured bulge into the left upper tibial epiphysis. On the right side it is seen that longitudinal trabecular architecture is prominent.

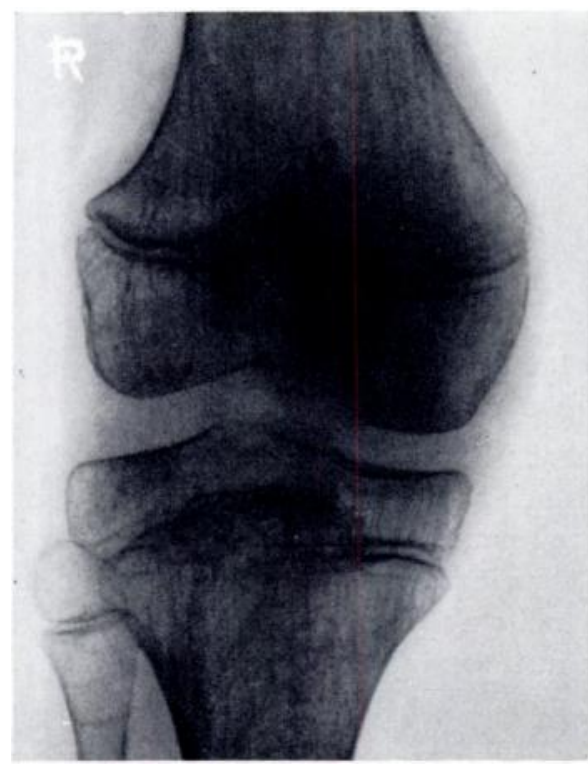

Fig. 5A

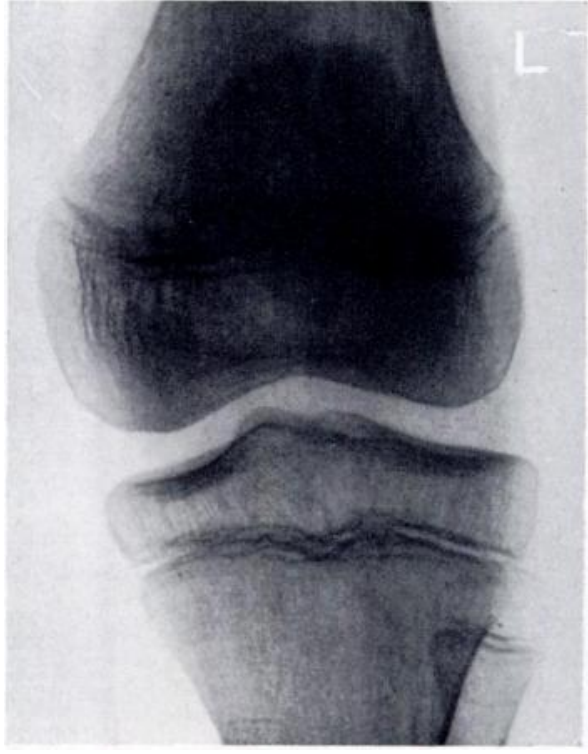

FIG. 5B

Case 84. Disease of the right hip joint with an unruptured bulge into the right upper tibial epiphysis of more than five years' duration; there is negligible interference with growth. 
the medullary contents of the shaft, then bulge upwards into this translucent area (Fig. 4). This may be termed the pre-fusion stage because premature fusion, though likely to follow, is not inevitable. A tibial bulge which must have been present for more than five years is shown in Fig. 5; the epiphysial line is grossly distorted but the translucent cartilaginous plate can still be traced over the bulge, and there is no marked interference with growth.

Premature fusion is inevitable when the limiting structures of the bulge rupture, and turn up like a flap into the translucent area in the epiphysis (Fig. 6). This allows the semi-

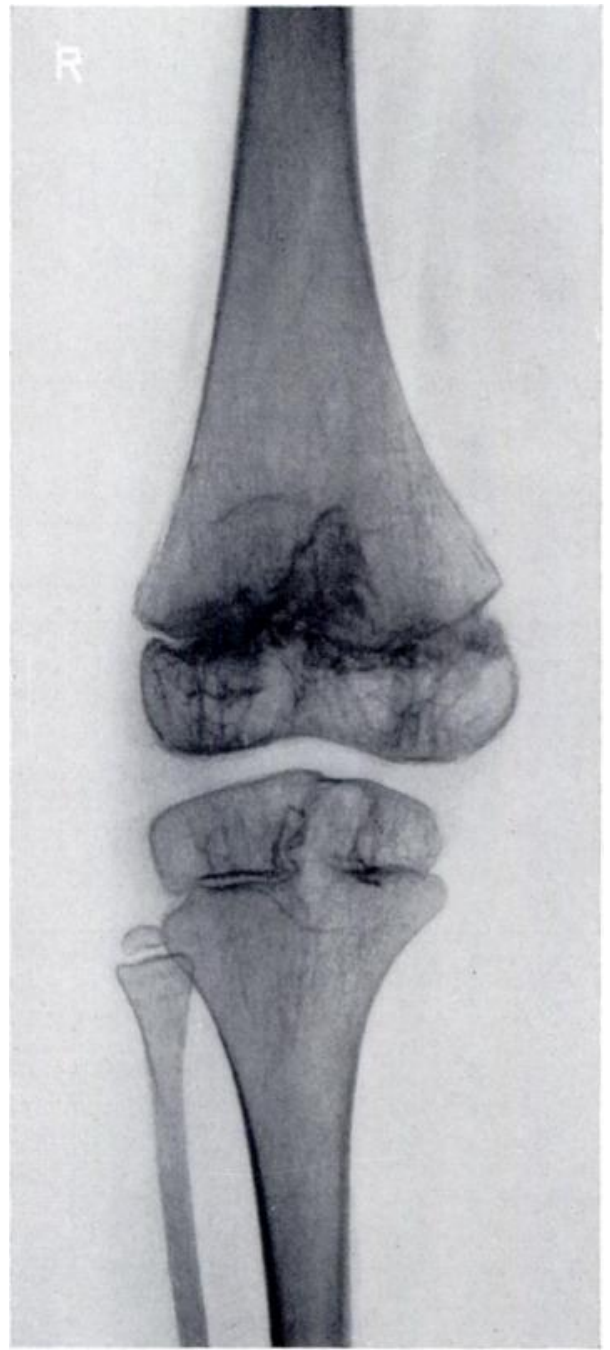

Fig. 6A

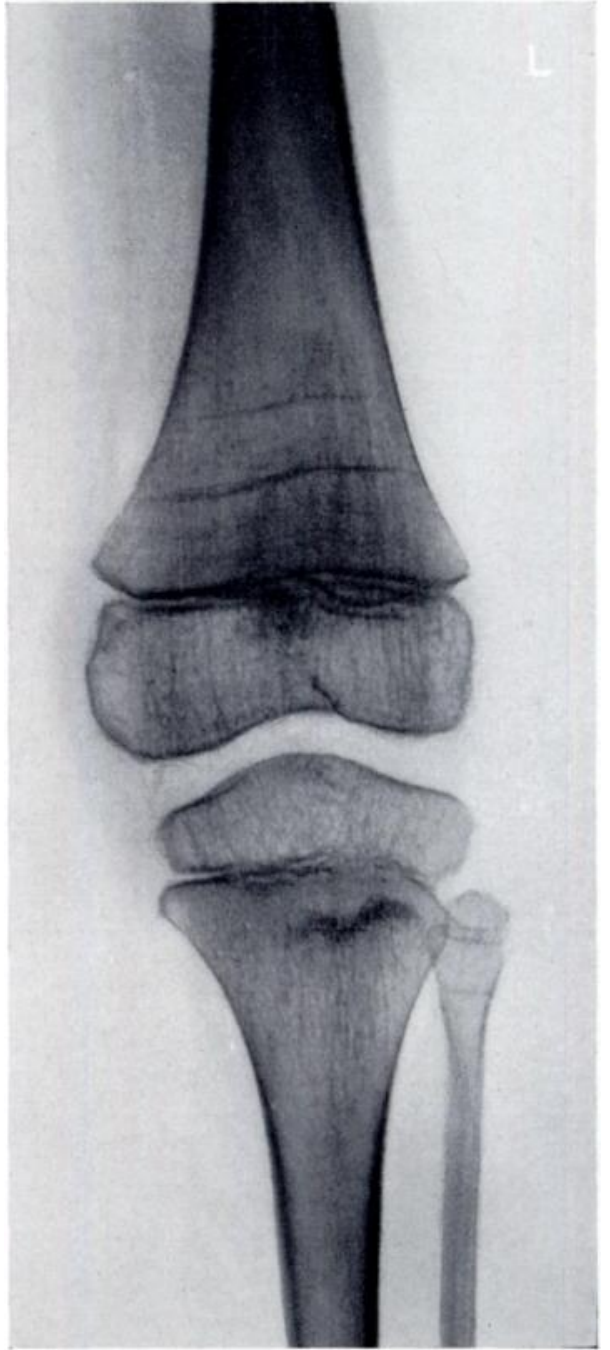

FIG. 6B

Case 38. Disease of the right hip joint showing a bulge into the right upper tibial epiphysis with rupture; and fragmentary fusion of the right lower femoral epiphysis.

fluid medullary contents of epiphysis and diaphysis to intermingle and establish a channel through which the blood supply of both can become continuous, now that the barrier of avascular cartilage has been removed. The laying down of bone trabeculae through this channel is not seen until a later date.

"Fragmentary type" of fusion-This type of fusion occurs more frequently in the femur, and is preceded by the same intense osteoporosis. Translucent areas appear, centrally in the diaphysis of the femur, and both subcortically and centrally in the epiphysis. Subcortical

vol. 31 B, No. 1, february 1949 
resorption occurs on the peripheral aspect of the vertical cancellous struts and does not abut to any extent on the terminal bone plate. The central translucent areas, both in epiphysis and diaphysis, are situated between the two cancellous struts and are larger, but less defined, than in the tibia. Premature fusion is indicated by the appearance of many small isolated fragments of calcific material replacing the crenated line of the terminal bone plate which normally is well defined and continuous. The thinned epiphysial cartilage plate disappears altogether in the area affected, and irregular linear shadows may be seen in the diaphysis (Fig. 6). In some cases there was difficulty in making certain that the cartilaginous plate was in fact obliterated, and that a false appearance was not being created by overlapping shadows. Oblique films were sometimes helpful but, where the evidence was still uncertain, repeated radiographic examination was made of the epiphysial lines. In securing early evidence of fusion, this was more valuable than radiographic estimations of bone length.

TABLE I

Frequency and Type of Premature Epiphysial Fusion at the Ipsilateral Knee in 91 Hips with Tuberculosis in 29 Cases from a total of 91 Tuberculous Hip Joints

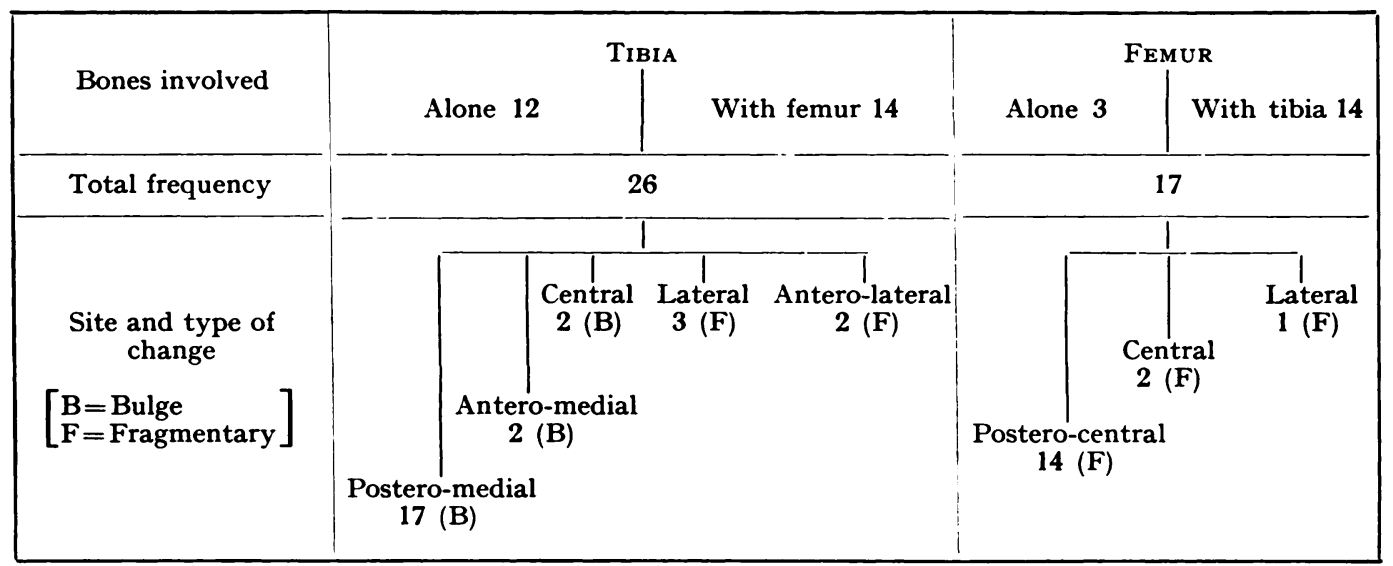

ANALYSIS OF PREMATURE EPIPHYSIAL FUSIONS

In this series of ninety-one tuberculous hip joints there were twenty-nine cases of premature fusion at the ipsilateral knee: fifteen right, fourteen left; fifteen male, and fourteen female. They have been divided into three groups according to the duration of epiphysial fusion: 1) late fusions - fifteen cases, all with radiographic evidence of a bone lock between epiphysis and diaphysis; 2) early fusions - eight cases, with ruptured bulges or fragmentary changes without evidence of a bone lock; in this group there was no deformity and no shortening; 3) doubtful fusions-six cases, with unruptured bulges or fragmentary changes in which evidence of destruction of the cartilaginous plate was uncertain (these have since been followed up for a year and all have fused).

Table I shows the frequency, type, and site of premature fusion. The tibial epiphysis was involved in twenty-six patients, and the femoral epiphysis in seventeen. Both bones were affected in fourteen cases, the tibia alone in twelve, and the femur alone in three. The bulge type of fusion was responsible for twenty-one out of twenty-six tibial fusions. The site of the original bulge was always postero-medial but, as it enlarged, extension took place anteriorly and laterally. Fragmentary types made up the remainder of the tibial fusions and they were confined to the antero-lateral or lateral portions of the epiphysial plate. Only the fragmentary type was seen in the femur. The change occurred postero-centrally or centrally in sixteen out of seventeen cases, and in the lateral half of the plate in the remaining 
case. In all, there were six patients with changes limited to the lateral half of the cartilaginous plates, but in no case in the series was the medial half affected alone.

With one exception, the femoral and tibial epiphyses in the normal limb did not show evidence of premature fusion; neither did the epiphyses at the ankle, or at the upper end of the fibula, even on the diseased side.

Relation of the duration of hip disease to premature fusion-In Table II the cases are classified according to the duration of hip disease. Of twenty-seven patients with disease of less than two years' duration, not one had either positive or doubtful evidence of premature fusion. There were thirty-six cases with a history of three to five years of disease and, with one exception, this group included all the examples of doubtful and early fusion. Of the twenty-one cases with disease lasting from six to ten years, there were nine with evidence of late epiphysial fusion and no examples of early or doubtful fusion. Every one of the seven cases

TABLE II

Incidence of Premature Epiphysial Fusion compared with Duration of Hip Disease

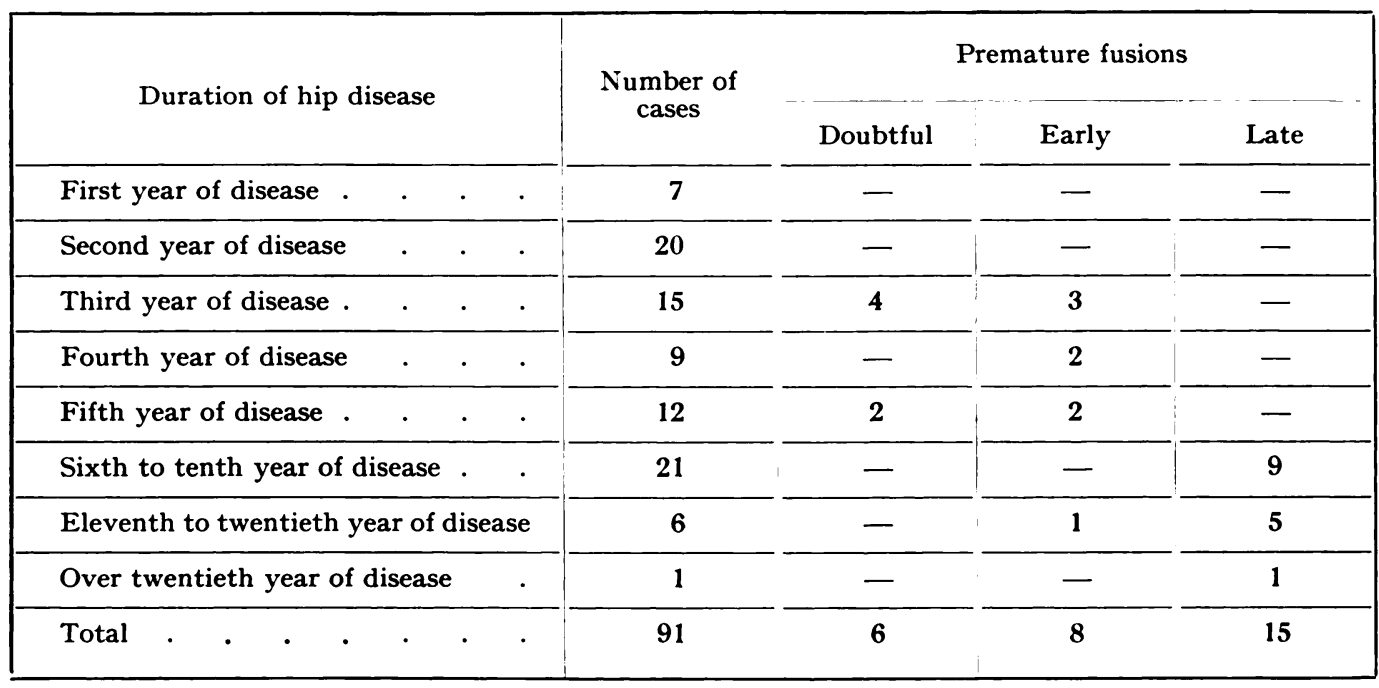

with a history of more than ten years showed premature fusion, six late and one early; the one case with early evidence of epiphysial change was an example of remission of hip disease after six years of complete freedom. It would seem that premature fusion does not occur during the first two years of the disease, and that early fusion develops some time between the third and fifth years.

Relationship of the age of the patient to premature fusion-The liability to premature fusion is not influenced by the age of the patient at the time of onset of hip disease. Every age group, up to thirteen years, was similarly affected.

Relationship of the severity of hip disease to premature fusion-In attempting to determine whether or not premature fusion was related to the severity of disease, the cases were classified into four groups: 1) typical disease, with early and marked destruction of the femoral head, acetabulum, or both; 2) low grade infection, without much bone destruction, but with recurrences and exacerbations; 3) extra-articular bone infection, with no evidence of joint involvement; 4) synovial tuberculosis with persistent osteoporosis. In Table III the incidence of premature fusion in the different types of disease is analysed, and it is evident that there is a close relationship with the severity. It occurs least frequently in extra-articular and synovial tuberculosis, and most frequently when there is typical disease with marked destruction of bone, especially when complicated by persistent sinus formation.

vol. 31 B, NO. 1, FEBRUARY 1949 

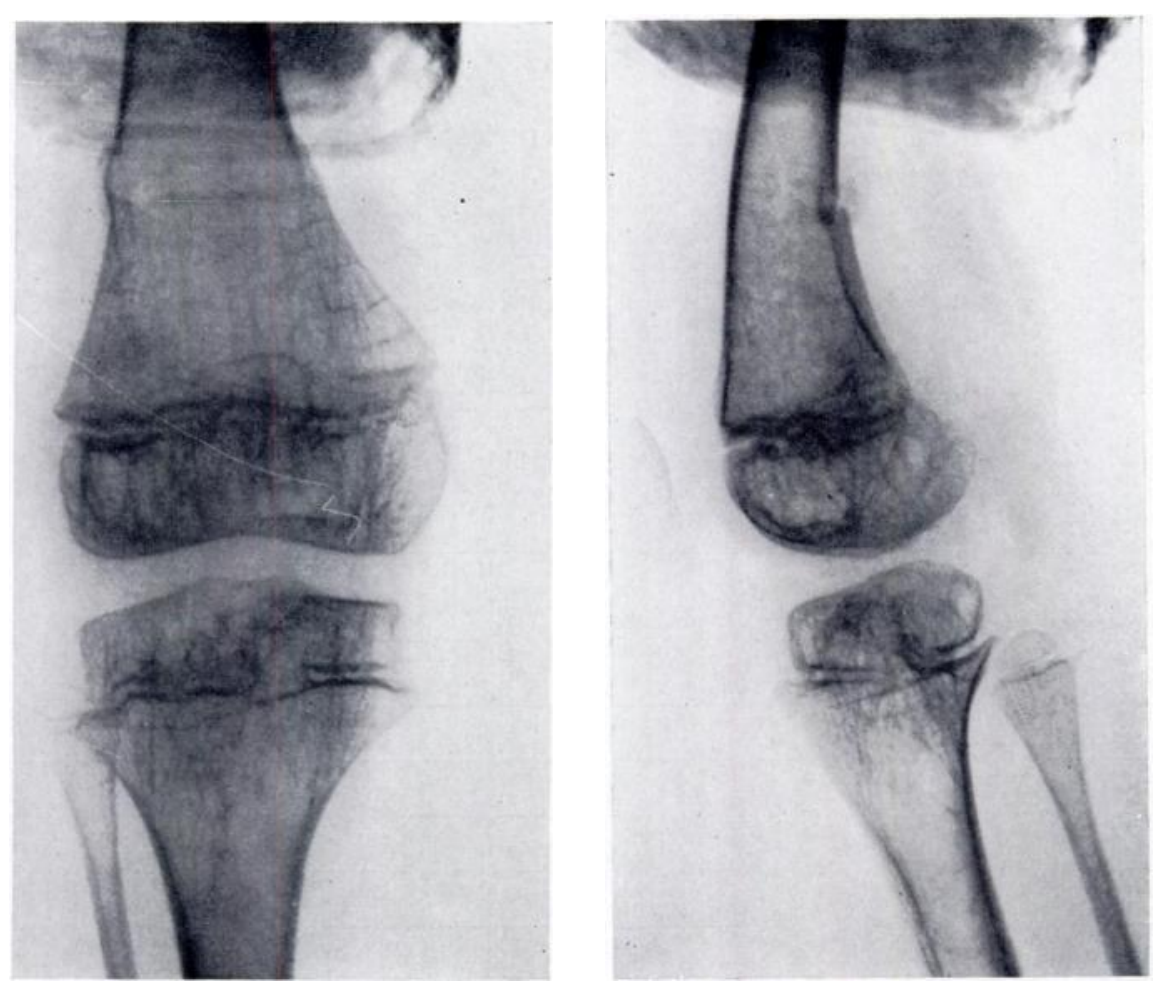

FIG. 7

Case 19. Disease of the left hip joint. A fracture was sustained through the lower third of the shaft of the femur. Radiographs taken at the time of fracture show that there was already a ruptured bulge in the upper tibial epiphysis.
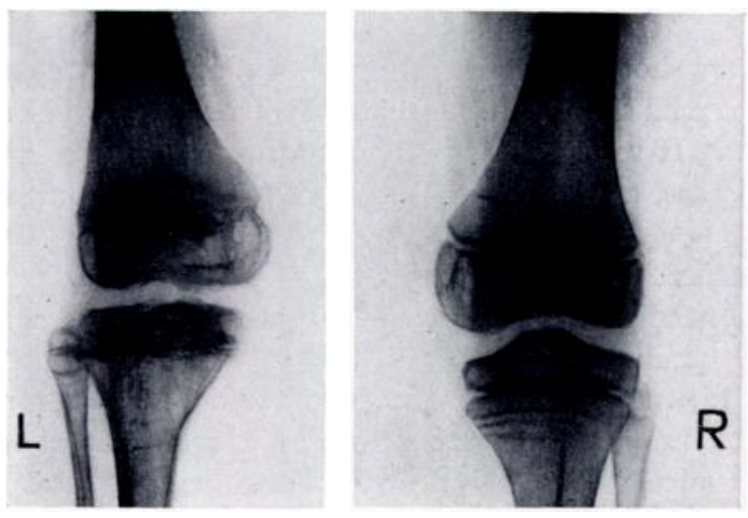

Fig. 8A

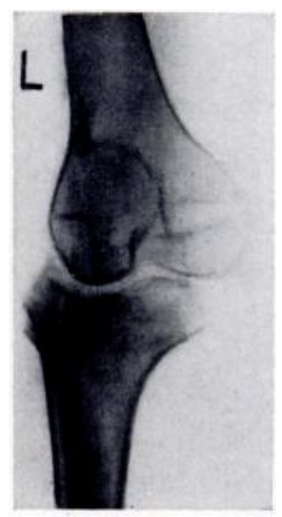

FIG. 8B

Case 19. One year later (Fig. 8A) there is evidence of "Boxing" and late fusion of the upper tibial epiphysis. Seven years later (Fig. 8B) is seen the typical result of premature fusion at the common site in the tibia. There is little or no interference with growth in the tibia. 


\section{DISCUSSION}

In this series of ninety-one tuberculous hip joints there were twenty-nine cases of premature epiphysial fusion at the knee. Reports from the United States of America include a series of one hundred and fifty tuberculous hip joints with ten premature fusions (Gill 1947), and ninety-two tuberculous hip joints with nine premature fusions (Ross 1948). From the series we have studied it would appear that the complication has occurred much less frequently in the United States than in this country, which may perhaps be due to the trend in contemporary American practice towards earlier operative interference by which to shorten the duration of treatment (McCarroll and Heath 1947, Pease 1947).

The bulge type of fusion, which occurs so often in the upper end of the tibia, is clearly due to rupture of the thinned cartilage plate, consequent upon local resorption of its cancellous support, as suggested by Gill (1944). The central fragmentary type, seen only in the femur, can be explained similarly; the only difference from the tibial bulge is that a more widely unsupported area of cartilage is subjected to resorption on both aspects. In the small number of fragmentary types, confined to the antero-lateral regions of the plates, constant compression appears to be the etiological factor because such fusions were not caused by resorption of cancellous support, and no corresponding involvement of the medial halves was observed.

TABLE III

Type and Severity of Hip Disease and its Relationship to Premature Epiphysial Fusion

\begin{tabular}{|c|c|c|c|c|c|c|c|c|}
\hline \multirow[b]{2}{*}{ Typical } & \multirow[b]{2}{*}{. } & \multirow[b]{2}{*}{. } & \multicolumn{2}{|c|}{$\begin{array}{l}91 \text { hips in the } \\
\text { series }\end{array}$} & \multicolumn{2}{|c|}{$\begin{array}{l}64 \text { cases of more } \\
\text { than } 2 \text { years' duration }\end{array}$} & \multicolumn{2}{|c|}{$\begin{array}{l}29 \text { cases of premature } \\
\text { epiphysial fusion }\end{array}$} \\
\hline & & & (57) & $63 \%$ & (43) & $67 \%$ & (23) & $79 \%$ \\
\hline Low grade . & . & . & $(22)$ & $24 \%$ & (15) & $23 \%$ & (4) & $13 \%$ \\
\hline Extra-articular & . & . & (4) & $4 \%$ & (3) & $5 \%$ & (1) & $3 \%$ \\
\hline Synovial & . & - & (8) & $\mathbf{9} \%$ & (3) & $5 \%$ & (1) & $3 \%$ \\
\hline Abscess & . & - & (13) & $14 \%$ & (13) & $20 \%$ & (6) & $20 \%$ \\
\hline Abscess anc & 1 sinus & • & (22) & $24 \%$ & (18) & $28 \%$ & (11) & $\mathbf{3 8} \%$ \\
\hline
\end{tabular}

Ross (1948) has shown that early disparity in the circumferential size of the bones of the two lower limbs is due to suppression of osteogenesis on the diseased side. The probable cause of this suppression is a permeation of toxins from the infection at the hip. The possibility that it is a reflex phenomenon, as suggested by John Hunter (1776) and elaborated by Vulpian (1866), cannot be dismissed; but the hypothesis of Kestler (1947), and the suggestion that there is tuberculous infiltration of the bones, are both untenable. Resorption, however, was a constant feature in both limbs, although always more advanced on the diseased side. Associated with it, changes in the cellular marrow lead to increased fluidity of the marrow contents-the " adipose osteoporosis" described by Cornil and Ranvier (1887). The more prolonged, the more continuous, and the more efficient the immobilisation, the greater were the changes produced. In one case, in which both lower limbs were immobilised continuously for five years, there was premature fusion of both tibial and femoral epiphyses in the affected limb and also of the tibial epiphysis of the normal limb (Fig. 9).

The effect of immobilisation in causing soft tissue atrophy has long been known. The pathology was discussed fully by Brackett (1891), who showed that patients with hip disease in whom movement had been permitted developed atrophy of the thigh-volume amounting to 1 per cent., and of the leg-volume to less than 1 per cent.; whereas patients treated by complete and rigid fixation developed atrophy of no less than 37 per cent. in the thigh, and 
17 per cent. in the leg. Bone, when immobilised for long periods and deprived of physiological stimuli, reacts in the same way as the softer tissues-a reaction which conforms with the laws of Wolff (1892). The more advanced resorptive changes occurring at the knee on the diseased side are caused by a combination of toxaemia and immobilisation.

The fundamental factors responsible for the bone changes causing premature epiphysial fusion are toxaemia from the infection at the hip, prolonged immobilisation, and the duration of action of either of these factors. It must be emphasized that no matter how severe the infection at the hip, premature fusion was never observed during the first two years of the disease.

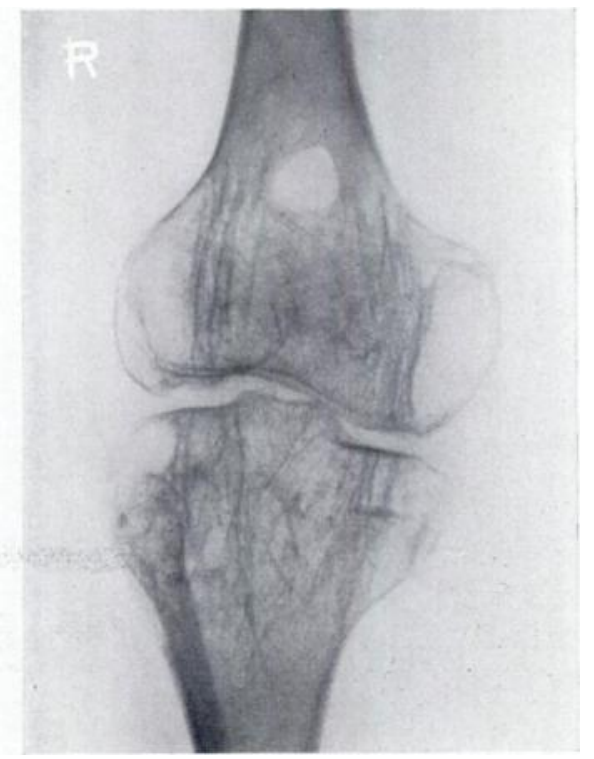

Fig. 9A

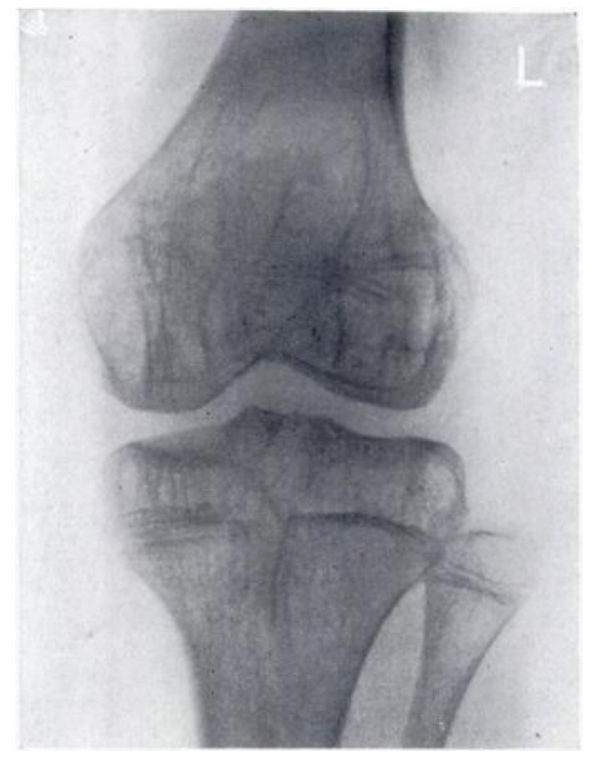

Fig. 9в

Case 17. Patient with disease of the right hip joint in whom both lower limbs had been immobilised for five years. There is premature fusion of both lower femoral and upper tibial epiphyses on the right side and of the upper tibial epiphysis on the left. Fusion took place between the ages of thirteen and sixteen years.

It is clear that injury, in quiescent disease, plays little or no part in the etiology of premature epiphysial fusion. Fusion occurred in seven early cases while the limbs were still immobilised, and before weight-bearing had begun. Of the five cases of premature fusion in which a pathological fracture occurred during early weight-bearing, four showed clear evidence that fusion had begun even before the fracture was sustained (Fig. 7); and in the fifth there was no immediate change in the epiphysial lines, or in the rate of fusion as compared with cases in which there had been no injury. The injury of operative intervention might at first appear to have increased the incidence of epiphysial fusion, because the complication occurred in ten of fourteen cases treated by extra-articular arthrodesis, and in five of six cases treated by late corrective osteotomy. But in all these cases it was clearly established that the onset preceded the operation. The time of onset of fusion corresponds with the later active phase of the disease. The only examples of premature fusion in which the factor of injury could not be excluded were those with adduction deformity of the hip joint treated by prolonged traction, especially when there was also knock-knee deformity. It was in these cases that premature fusion was limited to the lateral regions of one or other epiphysial plates.

The fact that in this considerable series of cases of premature fusion of the upper tibial and lower femoral epiphysis there has been no single example of premature fusion of the upper 
fibular epiphysis, and that no such fusion has been reported in the literature, is remarkable. It is unimportant that the fibula is not a weight-bearing bone, because, as we have seen, the complication occurs in the tibia and femur when there has been no weight-bearing. The immunity may perhaps be due to late appearance of the ossific nucleus of the fibular head, retarded still further by disease at the hip; or to the fact that the surface area of the epiphysial plate is so small, and the shaft so slender, that such loss of trabecular support as does occur is insufficient to weaken this area of cartilage to the point of rupture.

\section{CONGLUSIONS}

1. In tuberculous disease of the hip, premature epiphysial fusion at the knee joint is due to rupture of the epiphysial cartilaginous plates consequent upon resorption of cancellous support and suppression of osteogenesis.

2. In the tibia, premature fusion is usually preceded by near-central "bulging" of the metaphysial and tibial marrow through the epiphysial plate. In the femur, epiphysial changes preceding fusion are of a fragmentary type.

3. Injury, in quiescent disease, plays little or no part in the causation of premature epiphysial fusion.

4. The factors which are responsible for these changes-local toxaemia and prolonged immobilisation-must exist for not less than two years.

5. In cases which are treated conservatively for long periods the incidence of premature fusion, with serious shortening of the limb, is so high that the wisdom of such treatment must be reconsidered.

We express our sincere thanks to $\mathrm{Dr} \mathrm{J}$. Dobson, $\mathrm{Dr} \mathrm{J}$. K. Cameron, and $\mathrm{Dr} \mathrm{J}$. Crosbie who accorded us all the facilities of their hospitals, and gave us much help and encouragement. We would also express our gratitude to the orthopaedic surgeons of Liverpool who gave access to their cases so willingly; and to the radiographers, ward sisters, and nurses to whom our visits meant so much extra work.

\section{REFERENCES}

Brackett, E. G. (1891): Transactions of the American Orthopedic Association, 4, 61.

BrAckett, E. G. (1924): Journal of Bone and Joint Surgery, 6, 832.

Bum, A. (1905): Wiener Medizinische Presse, 46, 121.

Bum, A. (1906): Wiener Medizinische Presse, 47, 2609.

Cornil and Ranvier, quoted by Jones, T. (1887): Diseases of Bones. London: Smith, Elder \& Co.

Fairbank, H. A. T. (1927-28): British Journal of Surgery, 15, 138.

GiLL, G. G. (1944): Journal of Bone and Joint Surgery, 26, 272.

GILL, G. G. (1947): Journal of Bone and Joint Surgery, 29, 905.

Green, W. T., and Anderson, M. (1947): Journal of Bone and Joint Surgery, 29, 659.

Hunter, JoHN (1776): M.S. Lectures on Surgery.

Jones, Robert (1899): On the prevention of short leg in hip disease. John Bale, Sons, Danielson, Ltd.

Kestler, Otto C. (1947): Journal of Bone and Joint Surgery, 29, 788.

McCarroll, H. R., and Heath, R. D. (1947): Journal of Bone and Joint Surgery, 29, 889.

Park, Roswell (1891): Transactions of the American Orthopedic Association, 4, 95.

Pease, C. N. (1947): Journal of Bone and Joint Surgery, 29, 874.

Reidy, J. A., Lingley, J. R., GALl, E. A., and BARR, J. S. (1947) : Journal of Bone and Joint Surgery, $29,853$. Ross, D. (1948): Journal of Bone and Joint Surgery, 30 A, 103.

Vulpian, A. (1866): Leçons sur la physiologie générale et comparée du système nerveux faites au Museum d'histoire naturelle. Paris: Germer-Baillière.

Wilkinson, M. C. (1947): Lancet, 1, 831.

WolfF, J. (1892): Das Gesetz der Transformation der Knochen. Berlin: A. Hirschwald.

Wright, G. A. (1887): Hip Disease in Childhood. London: Longmans, Green \& Co. 